\title{
Capillary Electrophoresis Analysis of Organic Amines and Amino Acids in Saline and Acidic Samples Using the Mars Organic Analyzer
}

\author{
Amanda M. Stockton, Thomas N. Chiesl, ${ }^{1}$ Tim K. Lowenstein, ${ }^{2}$ \\ Xenia Amashukeli, ${ }^{3}$ Frank Grunthaner, ${ }^{3}$ and Richard A. Mathies ${ }^{1}$
}

\begin{abstract}
The Mars Organic Analyzer (MOA) has enabled the sensitive detection of amino acid and amine biomarkers in laboratory standards and in a variety of field sample tests. However, the MOA is challenged when samples are extremely acidic and saline or contain polyvalent cations. Here, we have optimized the MOA analysis, sample labeling, and sample dilution buffers to handle such challenging samples more robustly. Higher ionic strength buffer systems with $\mathrm{p} K_{\mathrm{a}}$ values near $\mathrm{pH} 9$ were developed to provide better buffering capacity and salt tolerance. The addition of ethylaminediaminetetraacetic acid (EDTA) ameliorates the negative effects of multivalent cations. The optimized protocol utilizes a $75 \mathrm{mM}$ borate buffer $(\mathrm{pH}$ 9.5) for Pacific Blue labeling of amines and amino acids. After labeling, $50 \mathrm{mM}$ (final concentration) EDTA is added to samples containing divalent cations to ameliorate their effects. This optimized protocol was used to successfully analyze amino acids in a saturated brine sample from Saline Valley, California, and a subcritical water extract of a highly acidic sample from the Río Tinto, Spain. This work expands the analytical capabilities of the MOA and increases its sensitivity and robustness for samples from extraterrestrial environments that may exhibit $\mathrm{pH}$ and salt extremes as well as metal ions. Key Words: Amino acid analysis-Astrobiology—Planetary exploration-Lab-on-a-chip-Micro total analysis systems. Astrobiology 9, 823-831.
\end{abstract}

\section{Introduction}

$\mathbf{E}$ XPLORATION OF MARS and other Solar System bodies for chemical signatures of life requires that we prepare for diverse and unexpected chemistries. In 1976, the Viking landers performed the first experiments to detect signs of past or present martian life. No organic molecules of martian origin were detected by its gas chromatograph-mass spectrometer (Biemann et al., 1977), and the biology experiments were considered ambiguous (Levin and Straat, 1977; Oyama and Berdahl, 1977). These observations have been attributed to sterilizing radiation (Benner et al., 2000), the presence of a strong oxidant in the regolith (Oyama and Berdahl, 1977; Zent and McKay, 1994), and the conversion of organic molecules to acids and amines during the pyrolysis extraction (Benner et al., 2000; Glavin et al., 2001). In 1997, the Pathfinder rover Sojourner characterized martian soil and rocks using X-ray fluorescence (Rieder et al., 1997) and identified and quantified a range of minerals in the regolith, including $\mathrm{MgO}(8 \%), \mathrm{CaO}(7 \%)$, and $\mathrm{FeO}(17 \%)$.
In 2004, the Mars Exploration Rover Opportunity discovered jarosite $(\mathrm{K}, \mathrm{Na}) \mathrm{Fe}_{3}\left(\mathrm{SO}_{4}\right)_{2}(\mathrm{OH})_{6}$ (Klingelhöfer et al., 2004) and other mineralogical evidence of ancient near-surface groundwater (Squyres et al., 2004). The strong acidity and salinity of the ancient groundwaters suggested by Opportunity's data do not preclude the potential of extinct life. For example, terrestrial extremophilic organisms thrive in environments that range from the hypersaline (3-5 M NaCl) (Chaban et al., 2006) to the highly acidic ( $\mathrm{pH}<2$ ) (Cavicchioli, 2002; Chaban et al., 2006) to the extremely cold $\left(-17^{\circ} \mathrm{C}\right)$ (Cavicchioli, 2002). Furthermore, Phoenix recently observed extant martian water ice near the northern martian pole.

Evidence of saline and acidic environments has also been found on other astrobiological targets. The significant amounts of $\mathrm{CO}_{2}$ measured by Cassini in Enceladus' watervapor plume (Waite et al., 2006) may be indicative of subsurface chemistry rich in carbonic acid. Spectra taken by Galileo's near-infrared mapping spectrometer of Europa's surface suggest that Europa is paved in areas with hydrated

\footnotetext{
${ }^{1}$ Department of Chemistry, University of California, Berkeley, California.

${ }^{2}$ Department of Geological Sciences and Environmental Studies, Binghamton University, Binghamton, New York

${ }^{3}$ Jet Propulsion Laboratories, California Institute of Technology, Pasadena, California.
} 
salts (McCord et al., 1998) and that sulfuric acid is a major component of its surface (Carlson et al., 1999). These challenging environments suggest that organic molecules and potential biomarkers, if present, will be at very low concentrations; thus it will be critical for future planetary exploration instruments to be as sensitive as possible while remaining independent of the input sample chemistry.

In the search for extraterrestrial life, amino acids are welljustified target molecules due to their ubiquity in life on Earth and the large amount of information that can be obtained from measurement of their concentration, composition, and chirality (Lu and Freeland, 2006). Racemic mixtures of amino acids have also been found in a number of extraterrestrial sources, including martian meteorites (Becker et al., 1999) and carbonaceous chondrite meteorites (Botta and Bada, 2002). Racemic mixtures indicate an abiological source, while homochiral amino acid composition provides strong evidence of extant or recently extinct life ( $\mathrm{Lu}$ and Freeland, 2006); the degree of their racemization provides a measure of the age of extinct biota (Bada and McDonald, 1995). However, it is important not to limit our search to a single compound class. Amines (Skelley et al., 2007), nucleobases (Skelley et al., 2006), polycyclic aromatic hydrocarbons (Stockton et al., 2009), and other organic molecules (Skelley and Mathies, 2003) are also important chemical markers and help to define whether the chemistry of an extraterrestrial sample is prebiotic, extant biotic, or extinct biotic.

The Mars Organic Analyzer (MOA) (Skelley et al., 2005) is a portable lab-on-a-chip microcapillary electrophoresis $(\mu \mathrm{CE})$ instrument that contains all the necessary microfluidics, optics, and electronics for capillary electrophoresis analysis. We have previously used the MOA to detect fluorescaminelabeled primary amines, amino acids (Skelley et al., 2005), nucleobases (Skelley et al., 2006), and polycyclic aromatic hydrocarbons (Stockton et al., 2009), and we have used it to determine the chirality of amino acids (Skelley and Mathies, 2003). The MOA was successfully field tested in the Panoche Valley, California (Skelley et al., 2005), and in the Atacama Desert (Skelley et al., 2007). Recent work, in which Pacific Blue succinimidyl ester (PB) was used as the labeling reagent, has enhanced MOA sensitivity to the parts-per-trillion level (Chiesl et al., 2009). PB labeling also enables the performance of micellar electrokinetic chromatography (MEKC) for pseudo-2-dimensional separations and thus dramatically enhances compositional analysis (Chiesl et al., 2009).

The application of the MOA to real-world samples requires that we enhance the robustness of the assay to varying sample characteristics. For example, samples with extreme salinity cause dispersive effects during $\mu \mathrm{CE}$ injection and lead to poor resolution and signal loss (Landers, 1997). Extremely acidic samples provide challenges due to inhibition of the labeling reaction (De Bernardo et al., 1974) and cessation of the electro-osmotic flow in the separation channels, both of which dramatically reduce signal. Furthermore, multivalent cations can alter the surface chemistry of the $\mu \mathrm{CE}$ channels and also lead to dispersive effects and electroosmotic flow inhibition (Brechtel et al., 1995). Since the concentrations of organic biomarkers expected on Mars may be low, it is crucial to enhance the MOA's tolerance to highly saline, acidic, or ionic samples. Here, we explore the assay conditions and buffers that are necessary to analyze samples containing high levels of acid, salts, and multivalent cations, and determine optimal labeling and analysis protocols. These optimized formats are then used to analyze two samples from representative extreme environments: saturated brine from Saline Valley, California, and a subcritical water extract from the acidic Río Tinto in Spain.

\section{Materials and Methods}

\section{Buffer and sample preparation}

Lithium carbonate, sodium tetraborate, and sodium phosphate were obtained from Sigma-Aldrich (St. Louis, MO). Stock solutions of $100 \mathrm{mM}$ carbonate, $100 \mathrm{mM}$ phosphate, and $400 \mathrm{mM}$ borate were prepared. The carbonate stock was adjusted to $\mathrm{pH} 8.5$ with $100 \mathrm{mM} \mathrm{HCl}$. Phosphate (pH 9.0) and borate ( $\mathrm{pH}$ 9.5) were used without $\mathrm{pH}$ adjustment. Both the disodium and tetrasodium salts of ethylaminediaminetetraacetic acid (EDTA) were obtained from Fischer Scientific (Pittsburgh, PA) and combined to produce a $250 \mathrm{mM}$, pH 7.0 aqueous stock solution. Racemic stock solutions $(20 \mathrm{mM}$ in water) were prepared for each amino acid (Sigma-Aldrich) and combined in appropriate volumes. Pacific Blue succinimidyl ester (ex. $405 \mathrm{~nm}$, em. $425 \mathrm{~nm}$ ) was obtained from Invitrogen (Carlsbad, CA), dissolved to $20 \mathrm{mM}$ in $\mathrm{N}, \mathrm{N}-$ dimethylformamide, and stored at $-20^{\circ} \mathrm{C}$. Fluorescamine (Sigma-Aldrich) stock solution $(20 \mathrm{mM})$ was prepared in dimethylsulfoxide (Sigma-Aldrich).

A stock solution of an amino acid standard containing equal $40 \mu M$ concentrations of citrulline, valine, serine, alanine, glycine, aspartic acid, and glutamic acid was prepared. Labeling reactions were conducted by combining one part each of the amino acid stock and buffer, then adding two parts PB stock solution. The labeling mixture was allowed to react overnight at room temperature before dilution for analysis. This standard was diluted to $400 \mathrm{nM}$ of each amino acid with the appropriate buffers for each experiment. Analysis was conducted by filling the separation column and wells with the analysis buffer then replacing the solution in the sample well with the diluted, labeled amino acid standard. Electropherograms were analyzed with PeakFit to determine the signal-to-noise, resolution, and peak efficiency in theoretical plates per meter for each amino acid peak.

To determine the effect of EDTA on labeling reaction, buffer solutions were prepared containing EDTA concentrations that ranged from 0 to $200 \mathrm{mM}$ in $30 \mathrm{mM}$ borate buffer ( $\mathrm{pH}$ 9.5). Reactions containing $20 \mu \mathrm{M}$ glycine and $400 \mu \mathrm{M}$ fluorescamine were conducted in these buffer solutions. After a 5-minute reaction, each sample was diluted to a final concentration of $133 \mathrm{n} M$ glycine, $2.7 \mu \mathrm{M}$ fluorescamine in its respective buffer. Fluorescence intensity measurements were then taken on a Jasco FP-750 spectrofluorometer.

Saline Valley and Río Tinto samples were labeled by a standard protocol and an optimized protocol. The optimized protocol consisted of combining $5 \mu \mathrm{l}$ of the sample with $20 \mu \mathrm{l}$ $75 \mathrm{mM}$ borate (pH 9.5) and adding $10 \mu \mathrm{l} \mathrm{PB}$ stock. After an overnight reaction at room temperature, water and $250 \mathrm{mM}$ EDTA were added to the labeled Río Tinto sample to provide a final 10-fold dilution with final EDTA and borate concentrations of $50 \mathrm{mM}$ and $30 \mathrm{mM}$, respectively. The Saline Valley sample was allowed to react for $30 \mathrm{~min}$; water was then added to provide a final 10-fold dilution of the sample with borate concentration of $30 \mathrm{mM}$. The standard method was conducted in an identical manner, with use of $4 \mathrm{mM}$ car- 
bonate buffer ( $\mathrm{pH}$ 8.5) in place of all borate and borate/EDTA buffers. Samples labeled via the optimized method were analyzed with $30 \mathrm{mM}$ borate in the separation column, and samples labeled via the standard method were analyzed with $4 \mathrm{mM}$ carbonate in the separation column.

Salt sample SV07-4 was obtained from Saline Valley, California (Lowenstein, 2007; Schubert et al, 2009), and was labeled according to both the standard method and the optimized protocol. A sediment sample from the Río Tinto, KF03-A, collected from a similar region as KF03-136 (Fernández-Remolar et al., 2005), was obtained as part of the Astrobiology Sample Analysis Program (ASAP) (Glavin et al., 2008). A subcritical water extraction was performed by collaborators at the Jet Propulsion Laboratory on $500 \mathrm{mg}$ of sample (Amashukeli et al., 2007). One-sixteenth of the total extract was freeze-dried and resuspended in $400 \mu \mathrm{l} 4 \mathrm{mM}$ carbonate, $\mathrm{pH} 8.5$ for analysis.

\section{Microdevice fabrication}

The microdevices were prepared as previously described (Skelley and Mathies, 2003; Skelley et al., 2005, 2006; Stockton et al., 2009). In summary, a sacrificial layer of polysilicon was deposited via chemical vapor deposition on a $10 \mathrm{~cm}$ borofloat glass wafer. A layer of photoresist was then spin-coated onto the wafer and patterned through a chrome mask by using a contact aligner. After the photoresist was developed, the exposed polysilicon was removed by plasma etching. Etching in buffered HF produced $23.6 \mathrm{~cm}$ long folded separation channels $100 \mu \mathrm{m}$ wide and $25 \mu \mathrm{m}$ deep. After removing photoresist, reservoir holes were drilled, the polysilicon layer was removed, and the wafer was bonded to a blank wafer to form completed channels. Injections were performed via a $1.2 \mathrm{~cm}$ long cross channel located $0.6 \mathrm{~cm}$ from the anode end of the channel. A $3 \mathrm{~mm}$ deep polydimethylsiloxane gasket with $4 \mathrm{~mm}$ diameter wells was placed over the reservoir holes to allow for larger volume. A schematic of the microdevice has been published and is presented in Supplemental Data (Chiesl et al., 2009; Stockton et al., 2009).

\section{Mars Organic Analyzer}

The Mars Organic Analyzer (Skelley et al., 2005) was used with minor modifications to the optical subsystem that allow for more sensitive analysis of amino acids (Chiesl et al., 2009; Stockton et al., 2009). The $404 \mathrm{~nm}$ laser was passed through a dichroic and focused to a 10-20 $\mu \mathrm{m}$ spot in the channel approximately $0.6 \mathrm{~cm}$ from the cathode reservoir. Fluorescence was collected by the objective and reflected by the dichroic through a long-pass filter onto a photomultiplier tube, which was digitized at $50 \mathrm{~Hz}$.

\section{Separation and injection procedures}

The microchip separation channel was prepared by first filling the sample, waste, and anode wells with running buffer. A vacuum was applied to the cathode well, which drew running buffer into the separation channel. The cathode well was then filled with running buffer, and the buffer in the sample well was drawn out and replaced with sample. Cross injection was accomplished by first applying a potential across the sample (ground) and waste $(-1000 \mathrm{~V})$ wells for $30 \mathrm{~s}$ with the anode and cathode grounded. This was followed by a
$200 \mathrm{~ms}$ step where the anode was floated. The separation was performed by applying $-15 \mathrm{kV}$ at the cathode, $-1.4 \mathrm{kV}$ at the sample and waste, and ground at the anode.

\section{Results}

\section{Initial buffer system selection}

The fluorescamine labeling reaction has an optimal $\mathrm{pH}$ range between 8.0 and 10.0 (De Bernardo et al., 1974). Since PB labeling proceeds via a similar reaction mechanism, the reaction buffers chosen for study had $\mathrm{p} K_{\mathrm{a}}$ values near the same range. Phosphoric acid has a $\mathrm{p} K_{\mathrm{a}}$ at 7.21 associated with the equilibrium between its diprotonated anion and monoprotonated anion. Borate has a $\mathrm{p} K_{\mathrm{a}}$ value of 9.23 due to its interaction with water. Each of these options provides a more suitable choice than carbonate $\left(\mathrm{p} K_{\mathrm{a}}\right.$ values $\left.6.37,10.25\right)$. Unacceptably high separation currents were observed with buffers containing greater than $50 \mathrm{mM}$ borate or $10 \mathrm{mM}$ phosphate concentrations. The following three buffer systems were chosen for study: $30 \mathrm{mM}$ borate in both the sample and the separation channel, $30 \mathrm{mM}$ borate in the separation channel with $5 \mathrm{mM}$ borate in the sample, and $5 \mathrm{mM}$ phosphate in the separation channel with $30 \mathrm{mM}$ borate in the sample.

\section{Effects of $\mathrm{NaCl}$ in the sample}

Electropherograms shown in Fig. 1 reveal the effect of high concentrations of salt in the sample. The high-salt

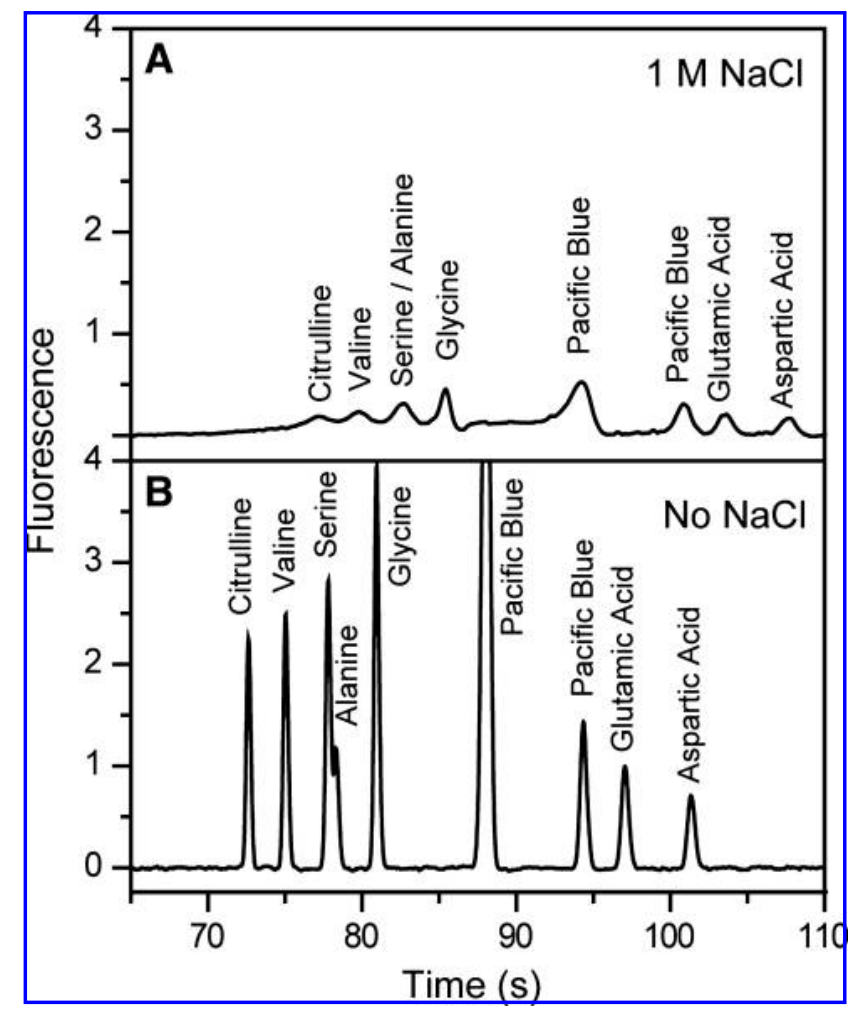

FIG. 1. Electropherograms of an amino acid standard with (A) and without (B) $1 \mathrm{M} \mathrm{NaCl}$. The separation channel and sample buffer contained $5 \mathrm{mM}$ borate buffer, $\mathrm{pH}$ 9.5. The standard contained $2 \mu M$ each citrulline, valine, serine, alanine, glycine, aspartic acid, and glutamic acid labeled with Pacific Blue. 


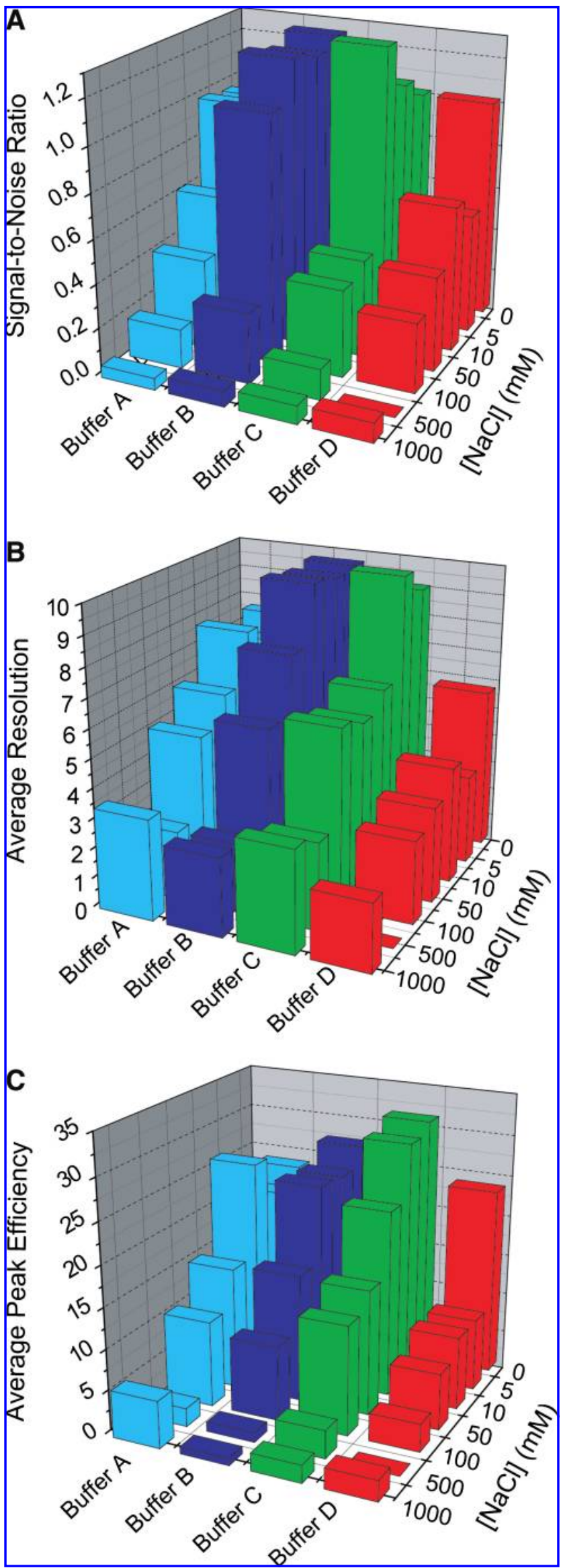

sample exhibits lower signal, broader peaks, and reduced resolution compared to the experiment performed with no $\mathrm{NaCl}$ in the sample solution. The signal-to-noise ratios, resolutions, and peak efficiencies for the amino acids were then determined for each $\mathrm{NaCl}$ concentration and buffer system and are summarized in Fig. 2. All four buffer systems showed a significant decline in all three parameters with increasing sample $\mathrm{NaCl}$, with the $5 \mathrm{mM}$ borate system (Buffer D) displaying the most significant decline. While the buffer system containing $5 \mathrm{mM}$ phosphate in the separation channel and $30 \mathrm{mM}$ borate in the sample (Buffer B) retained the best signal-to-noise ratio with increasing sample $\mathrm{NaCl}$, the buffer system containing $30 \mathrm{mM}$ borate in both the separation channel and the sample (Buffer $\mathrm{C}$ ) retained the best resolution and peak efficiencies. Because of its operational simplicity, the latter buffer system was chosen for further optimization.

\section{Effects of multivalent cations and EDTA}

Studies of samples containing additional contaminating salts, including $\mathrm{Na}_{2} \mathrm{SO}_{4}, \mathrm{MgCl}_{2}, \mathrm{NaClO}_{4}, \mathrm{FeCl}_{3}$, and $\mathrm{CaCl}_{2}$, indicated that the anion has a negligible effect on the separation quality. However, multivalent cations were found to reduce the signal significantly even at concentrations as low as $5 \mathrm{mM}$. We therefore added EDTA to the sample buffer to chelate these cations and counteract their effect, as illustrated with the use of $\mathrm{Mg}^{2+}$ as a model cation in Fig. 3. The sample used for the top electropherogram (A) contained both $5 \mathrm{mM}$ $\mathrm{MgCl}_{2}$ and $10 \mathrm{mM}$ EDTA; full signal strength and high separation quality were observed. The $5 \mathrm{mM} \mathrm{MgCl} 2$ sample used for the bottom trace (B) did not contain EDTA; therefore, signal was not obtained. An optimization experiment was conducted varying the EDTA and $\mathrm{MgCl}_{2}$ concentration (Fig. 4). When the $\mathrm{MgCl}_{2}$ concentration was higher than the EDTA concentration, no signal was observed, as expected. When the $\mathrm{MgCl}_{2}$ concentration was equal to the EDTA concentration, some peaks were observed, but with lower signals and reduced resolution and peak efficiency. When the EDTA concentration was greater than the $\mathrm{MgCl}_{2}$ concentration, signal, peak efficiency, and resolution were restored. However, the signal and other performance characteristics tended to decrease as the EDTA concentration was further increased. Experiments in which $\mathrm{FeCl}_{3}$ (Supplemental Data Fig. S03) was used exhibited similar trends.

FIG. 2. Effects of sample salt content on separation performance with use of selected buffering systems. Buffer A consisted of $30 \mathrm{mM}$ borate in the separation channel and $5 \mathrm{mM}$ borate in the sample. Buffer B consisted of $5 \mathrm{mM}$ phosphate in the separation channel and $30 \mathrm{mM}$ borate in the sample. Buffer C consisted of $30 \mathrm{mM}$ borate in both the separation channel and the sample. Buffer D consisted of $5 \mathrm{mM}$ borate in both the separation channel and the sample. (A) Average signal-to-noise of all amino acid peaks normalized to the no-salt case for each buffer. (B) Average resolution between amino acid peaks for each buffer system at the indicated concentrations of $\mathrm{NaCl}$. (C) Average amino acid peak efficiency in theoretical plates-per-meter $\left(\times 10^{-4}\right)$ for each buffer system at the indicated concentrations of $\mathrm{NaCl}$. The sample is the same as Fig. 1. Color images available online at www.liebertonline.com/ast. 


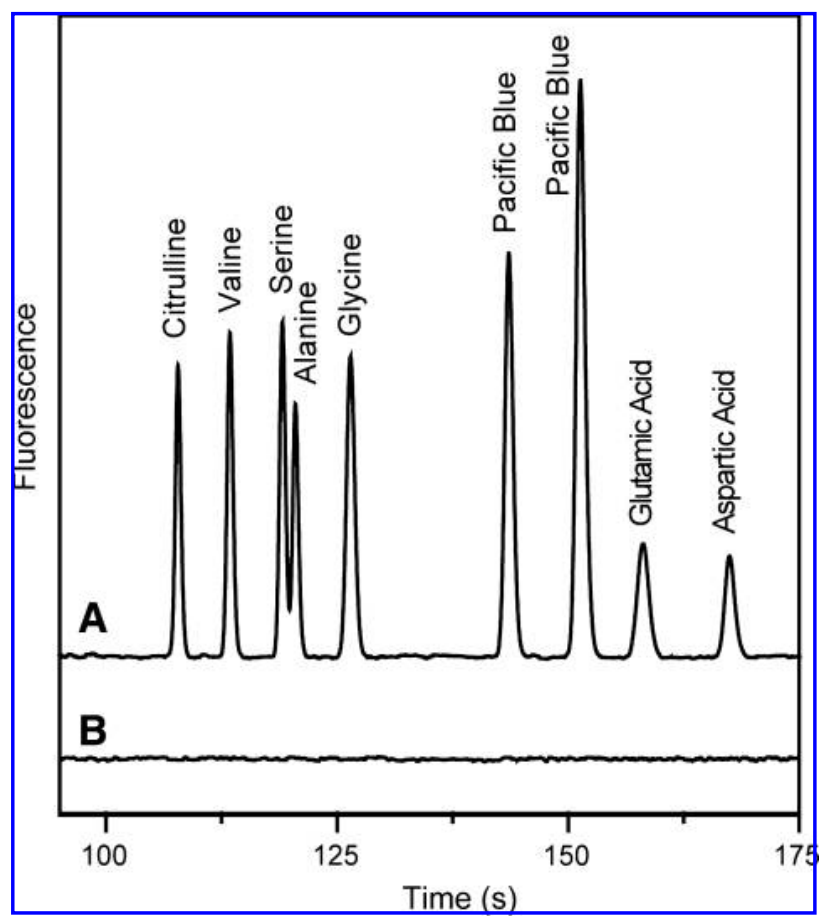

FIG. 3. Electropherograms of a standard containing $5 \mathrm{mM}$ $\mathrm{MgCl}_{2}$ with $10 \mathrm{mM}$ EDTA (A) and without EDTA (B). The separation column and sample contained $30 \mathrm{mM}$ borate buffer, $\mathrm{pH}$ 9.5. The sample contained $2 \mu \mathrm{M}$ each citrulline, valine, serine, alanine, glycine, aspartic acid, and glutamic acid labeled with Pacific Blue.

Based on these results, an EDTA concentration of $50 \mathrm{mM}$ was chosen as the optimal concentration for further studies.

\section{Effects of EDTA on labeling}

The fluorescent signal of a solution of an amino acid and fluorescamine provides a convenient measure of the extent of the amino acid labeling reaction. Fluorescence measurements were made in buffers containing $30 \mathrm{mM}$ borate and EDTA concentrations that ranged from 0 to $200 \mathrm{mM}$ (Fig. S04 in Supplemental Data). There was a significant decline in labeling efficiency in samples containing EDTA; the higher the concentration of EDTA, the stronger the inhibition. While exploring the reason for EDTA inhibition of the labeling reaction is beyond the scope of this work, it may be due to decreased cationic species available to stabilize the negatively charged tetrahedral intermediate formed when an amino compound attacks the carbonyl carbon in the first step of the labeling reaction mechanism. We conclude that the

FIG. 4. Effects of different EDTA and $\mathrm{MgCl}_{2}$ concentrations in the sample buffer on separation performance. The separation channel and sample contained $30 \mathrm{mM}$ borate buffer, $\mathrm{pH}$ 9.5. (A) Average signal-to-noise of all amino acid peaks normalized to the no-salt, no-EDTA case. (B) Average resolution between amino acid peaks for each concentration of EDTA and $\mathrm{MgCl}_{2}$. (C) Average peak efficiency in theoretical platesper-meter $\left(\times 10^{-4}\right)$ of amino acid peaks for each concentration of EDTA and $\mathrm{MgCl}_{2}$. The sample is the same as in Fig. 3 . Color images available online at www.liebertonline.com/ast.

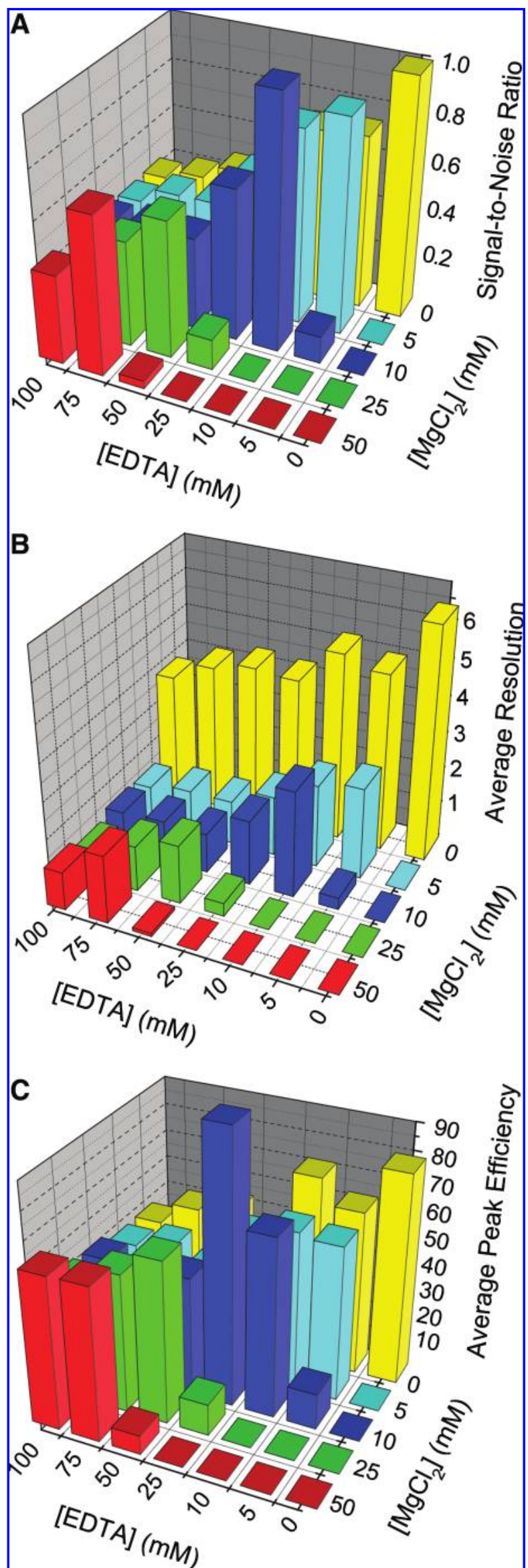




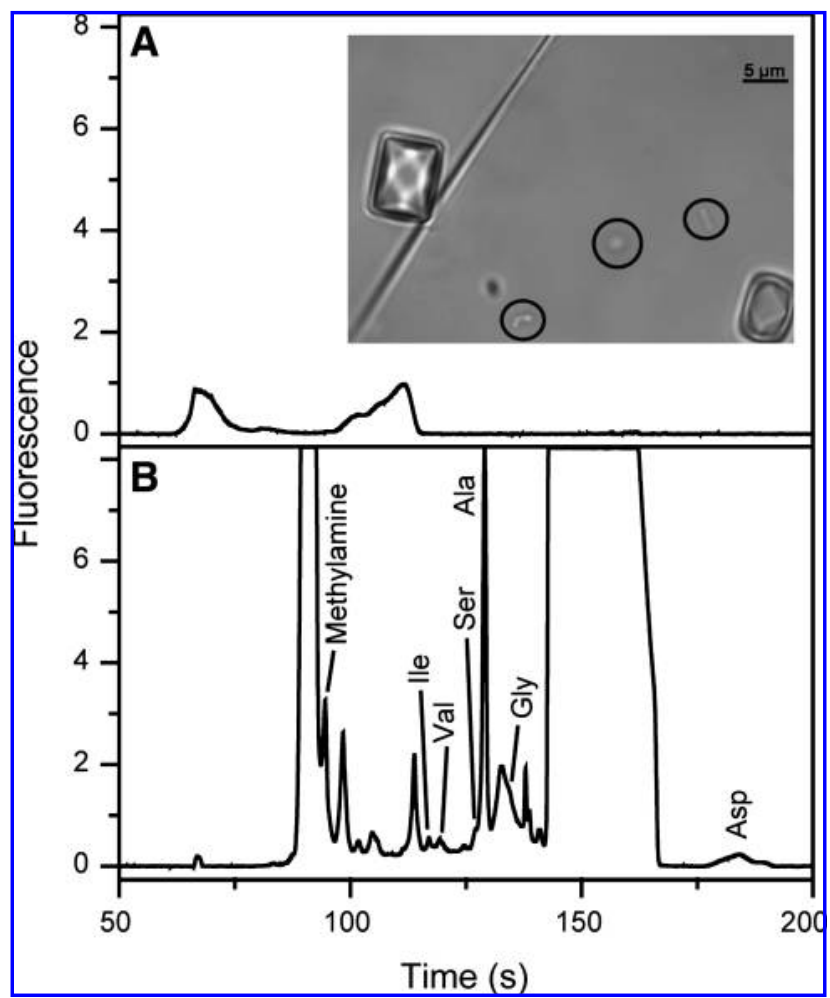

FIG. 5. Analysis of Saline Valley brine SV07-4. (A) Electropherogram of Pacific Blue labeled sample with the separation channel and sample containing $4 \mathrm{mM}$ carbonate, $\mathrm{pH}$ 8.5. The inset presents a photomicrograph of a wet mount viewed with a $100 \times$ oil immersion lens. Prokaryote cells occur as rod and coccoid shapes (circled); halite (cube) and mirabilite (needle) crystallized from the $\mathrm{Na}-\mathrm{Cl}-\mathrm{SO}_{4}$-rich brine after collection. Scale bar is $5 \mu M$. (B) Electropherogram of Pacific Blue labeled sample, where the separation channel contained $30 \mathrm{mM}$ borate, $\mathrm{pH}$ 9.5, and the sample contained $30 \mathrm{mM}$ borate, $50 \mathrm{mM}$ EDTA, pH 9.5. Ala, alanine; Asp, aspartic acid; Gly, glycine; Ile, isoleucine; Ser, serine; Val, valine.

optimal labeling buffer should not contain EDTA because the positive effects of EDTA can be achieved by dilution after reaction.

\section{Analysis of Saline Valley and Río Tinto samples}

Two samples that exhibited extreme salinity and acidity were chosen to test the robustness of the optimized buffer system. The high-salinity sample was a halite saturated brine, SV07-4, from Saline Valley, California (Fig. 5). This sample was of particular interest because it contained halophilic archaea and bacteria (Schubert et al., 2009). An image of the brine taken with a 100x oil-immersion lens shows several prokaryote cells (rod and coccoid shapes) accompanying cubic halite $(\mathrm{NaCl})$ crystals and a mirabilite $\left(\mathrm{Na}_{2} \mathrm{SO}_{4} 10 \mathrm{H}_{2} \mathrm{O}\right)$ needle (Fig. 5A). Despite the abundance of prokaryote cells, electropherograms of the MOA analysis of these $\mathrm{Na}-\mathrm{Cl}-\mathrm{SO}_{4}$-rich brines via the standard protocol (Fig. 5A) exhibit extremely low signal amino acid peaks because of the high salt concentration (saturated with halite and mirabilite). Electropherograms obtained via the optimized protocol show significantly increased peak intensities (Fig. 5B), which allow for the identification and quantification of
Table 1. Amino Acid Analysis of Challenging Samples

\begin{tabular}{lcc}
\hline Amine/amino acid & $\begin{array}{c}\text { Río Tinto }^{\mathrm{a}} \\
(\text { KF03-136, } p p b)\end{array}$ & $\begin{array}{c}\text { Saline Valley }^{\mathrm{b}} \\
(\text { SV07-4, } \mu \mathrm{M})\end{array}$ \\
\hline Ammonia & 9,520 & $\mathrm{ND}^{\mathrm{c}}$ \\
Methylamine & 809 & 200 \\
Ethylamine & 3,640 & $\mathrm{ND}^{\mathrm{c}}$ \\
Leucine + Isoleucine & 136 & $\mathrm{ND}^{\mathrm{c}}$ \\
Valine & 418 & 4.3 \\
Serine & 19,800 & 11 \\
Alanine & 855 & 210 \\
Glycine & 6,200 & 0.48 \\
Aspartic acid & 717 & 27
\end{tabular}

${ }^{\mathrm{a} C}$ Composition calculated as a fraction of initial sample assuming $100 \%$ recovery during the subcritical water extraction and subsequent processing.

${ }^{\mathrm{b}}$ Concentrations of detected species in the received saturated brine solution.

'Species not reported because either they were not observed or they were observed with signal at or below that in a buffer blank.

multiple amino acids in the brine solution. The amino acid composition and concentrations in this sample are shown in Table 1.

The Río Tinto in Spain provides an example of both high salinity and extreme acidity. The sample $\mathrm{pH}$ is less than 2 , and it contains high iron, magnesium, and general salts with concentrations greater than $500 \mathrm{mM}$ (Fernández-Remolar et al., 2005), which makes $\mu \mathrm{CE}$ amino acid analysis challenging. A subcritical water extract of the Río Tinto sample KF03-A was analyzed with the standard and optimized assays. Electropherograms obtained with the standard protocol (Fig. 6B) exhibit low signal and an absence of peaks eluting after $\sim 150 \mathrm{~s}$. However, analysis in which the optimized buffer system was used (Fig. 6A) showed much stronger amine and amino acid signals, allowing for substrate identification and quantification (Table 1). In KF03-A, ammonia, ethylamine, serine, and glycine were present in partsper-trillion levels, while methylamine, valine, alanine, and aspartic acid were present in high parts per billion. The complexity of the trace and the large levels of amines and amino acids in this sample were likely derived from a thriving acidophile population. This improvement in analytical capability was due to improved buffering against the high acid concentration, chelation by EDTA of multivalent cations (e.g., $\mathrm{Mg}^{2+}, \mathrm{Fe}^{3+}$ ), and increased resistance to deleterious salt effects in the injection and separation.

\section{Discussion}

The optimized MOA analysis protocol developed here provides several benefits over our previous methods. The $5 \mathrm{mM}$ borate buffer system used in the salt experiments is most similar to the previously used $4 \mathrm{mM}$ carbonate buffering system (Chiesl et al., 2009). With no $\mathrm{NaCl}$ present in the sample, there was no mismatch in ionic strength between the sample matrix and the separation buffer, so there was little difference between the $5 \mathrm{mM}$ borate buffer and the other buffer systems tested. However, at higher sample $\mathrm{NaCl}$ concentrations, the mismatch in ionic strengths of the sample and separation column produced intense dispersive effects when using the $5 \mathrm{mM}$ borate system. Because the ionic 


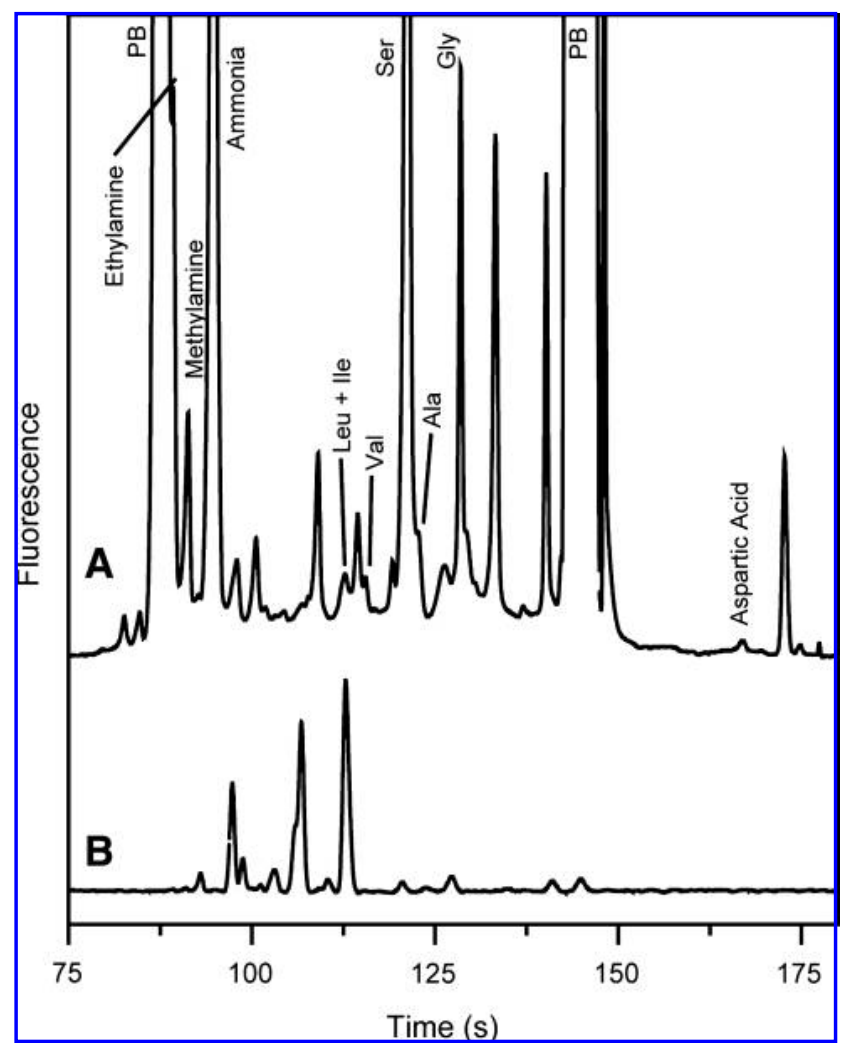

FIG. 6. Electropherograms of a Pacific Blue labeled subcritical water extract of the Río Tinto sample KF03-A (Fernández-Remolar et al., 2005). The sample was diluted 5-fold with sample buffer before labeling then analyzed at a total dilution factor of 10-fold. (A) Separation channel contained $30 \mathrm{mM}$ borate, $\mathrm{pH}$ 9.5. The sample was diluted with $30 \mathrm{mM}$ borate before labeling then brought to a final sample buffer composition of $30 \mathrm{mM}$ borate, $50 \mathrm{mM}$ EDTA for injection. (B) Separation and sample buffer are both $4 \mathrm{mM}$ carbonate, $\mathrm{pH}$ 8.5. Ala, alanine; Gly, glycine; Ile, isoleucine; Leu, leucine; Ser, serine; Val, valine.

strength of the separation buffer was higher for the $30 \mathrm{mM}$ borate system, the mismatch was reduced, and dispersive band broadening was less pronounced.

The $30 \mathrm{mM}$ borate system has a larger capacity than the $4 \mathrm{~m} M$ carbonate system, so it can buffer a significantly larger concentration of acid or base present in a sample. The larger buffer capacity is partly due to the higher concentration of buffer salt: $30 \mathrm{mM}$ borate in the optimized system compared to $4 \mathrm{mM}$ carbonate in the previous system. However, it also arises from a better choice of the buffer $\mathrm{p} K_{\mathrm{a}}$ values relative to the operating $\mathrm{pH}$. The carbonate buffer was used at $\mathrm{pH} 8.5$, which is well out of its effective buffering range $\left(\mathrm{p} K_{\mathrm{a}} 6.4\right)$. The borate buffer has a $\mathrm{pK}_{\mathrm{a}}$ (9.23) that is significantly closer to the operating $\mathrm{pH}$ of 9.5 .

To ensure that analysis is not compromised by the presence of divalent cations, it is essential to have some EDTA in the sample buffer. While the presence of EDTA reduces signal, the complete loss of signal seen with even a $5 \mathrm{mM}$ addition of $\mathrm{Mg}^{2+}$ makes the 10-50\% EDTA-induced loss in signal and separation quality acceptable. It is also interesting to note that divalent cations appear to counter the deleterious effect of EDTA on the separation, as nearly full signal, resolution, and peak efficiency are restored when the EDTA concentration is just higher than the $\mathrm{MgCl}_{2}$ concentration. Although EDTA also has an inhibitory effect on sample labeling, it is easy to circumvent this problem by adding EDTA to the sample after the labeling reaction is complete.

The net benefits of the optimized method over the standard method are best demonstrated by the analysis of terrestrial samples with extremes of salinity and $\mathrm{pH}$. The high-salt sample used was brine taken from the saline pan of Saline Valley. The sampling site hosts a diverse community of single-celled halophilic algae (genus Dunaliella) and halophilic bacteria and archaea; thus we would expect large concentrations of amino acids (Lowenstein, 2007; Schubert et al., 2009). This sample was $\mathrm{pH}$ neutral and did not contain significant levels of divalent cations, so high salt concentrations $\left(\mathrm{Na}^{+}, \mathrm{Cl}^{-}\right.$, and $\mathrm{SO}_{4}^{2-}$ at halite and mirabilite saturation) were the major concern. Analysis with our previous method showed low signal and peak broadening, which makes amino acid identification and quantitation impossible. The analysis via the optimized protocol, however, allowed for identification of several amino acids and quantitation of total amino acid content at $450 \mu \mathrm{M}$. This result is a significant advance in the MOA capabilities because it demonstrates the potential for the direct analysis of aqueous extracts without extensive preprocessing (Kminek et al., 2000; Amashukeli et al., 2007).

The Río Tinto in Spain has a pH less than 2 and contains high concentrations of metal salts (Amaral Zettler et al., 2002). Despite these seemingly hostile characteristics, the Río Tinto hosts a rich ecosystem, with a surprising degree of eukaryotic diversity (Amaral Zettler et al., 2002), and thus high levels of amino acids and organic amines are expected (Glavin et al., 2008). The extreme acidity of this concentrated ASAP (Glavin et al., 2008) sample severely inhibited labeling via the previous protocol, and the high metal content severely limited the injection, which resulted in low signal. In our Río Tinto extract analysis for the ASAP (Glavin et al., 2008), the sample was manually neutralized before labeling and analyzed via the standard protocol, but the electropherogram still shows low signal strength because of the high salt concentration resulting from neutralization and the high metal content.

In contrast, the optimized method employed here to analyze the Río Tinto sample required no neutralization before labeling and produced traces with high signal strength. This improvement is seen because of the much larger buffering capacity of the optimized buffering system and the addition of EDTA to the sample buffer after labeling to negate effects of the sample's exceptionally high metal content. The unusually high abundance of serine in this sample raises the question whether the subcritical water extraction method, salts, a coeluting amine, or an analytical artifact may increase the intensity of this peak. While this assignment was confirmed by coelution of a serine spike, additional 2dimensional capillary electrophoresis separations with MEKC (Chiesl et al., 2009) and mass spectrometry would provide valuable confirmation.

The optimized buffer system developed here should also be useful for chiral separations of labeled amino acids. The improved buffering system should facilitate separation of fluorescamine labeled amino acids in cyclodextrin buffers that have been shown to provide chiral resolution (Skelley 
and Mathies, 2003). Chiral separations of PB labeled amino acids conducted with MEKC (Chiesl et al., 2009) should also exhibit decreased sensitivity to sample salt and $\mathrm{pH}$ once the detailed conditions are optimized.

\section{Conclusions}

This work demonstrates that proper buffering is critical for successful sample analysis and that amino acid extracts obtained from samples from extreme environments can be directly injected into the MOA $\mu \mathrm{CE}$ instrument and analyzed. These new methods critically advance the development of our analytical system for biomarker detection providing broad applicability and versatility for planetary exploration. For more information on MOA development, see http://astrobiology.berkeley.edu.

\section{Acknowledgments}

We thank Daniel Glavin (NASA Goddard Space Flight Center) and Mary Sue Bell (NASA Johnson Space Center) for providing ASAP sample KF03-A from the Río Tinto. Microdevices were fabricated in the UC Berkeley Microfabrication Laboratory by Wai K. Chu. This research was supported by NASA grants NNG04GB75G and NNX08AR09G, NSF grant EAR 0433802 (T.K.L.), and by the Jet Propulsion Laboratory and the California Institute of Technology under contract 1297596.

\section{Author Disclosure Statement}

A.M. Stockton, T.N. Chiesl, T.K. Lowenstein, X. Amashukeli, F. Grunthaner, and R.A. Mathies declare no competing financial interest.

\section{Abbreviations}

ASAP, Astrobiology Sample Analysis Program; EDTA, ethylaminediaminetetraacetic acid; $\mu \mathrm{CE}$, microcapillary electrophoresis; MEKC, micellar electrokinetic chromatography; MOA, Mars Organic Analyzer; PB, Pacific Blue succinimidyl ester.

\section{Supplemental Data}

Additional data as noted in the text is available online at www.liebertonline.com/ast.

\section{References}

Amaral Zettler, L.A., Gómez, F., Zettler, E., Keenan, B.G., Amils, R., and Sogin, M.L. (2002) Eukaryotic diversity in Spain's River of Fire. Nature 417:137.

Amashukeli, X., Pelletier, C.C., Kirby, J.P., and Grunthaner, F.J. (2007) Subcritical water extraction of amino acids from Atacama Desert soils. J. Geophys. Res. 112:1-10.

Bada, J.L. and McDonald, G.D. (1995) Amino acid racemization on Mars: implications for the preservation of biomolecules from an extinct martian biota. Icarus 114:139-143.

Becker, L., Popp, B., Rust, T., and Bada, J.L. (1999) The origin of organic matter in the martian meteorite ALH84001. Earth Planet. Sci. Lett. 167:71-79.

Benner, S.A., Devine, K.G., Matveeva, L.N., and Powell, D.H. (2000) The missing organic molecules on Mars. Proc. Natl. Acad. Sci. U.S.A. 97:2425-2430.
Biemann, K., Oro, J., Toulmin, P., III, Orgel, L.E., Nier, A.O., Anderson, D.M., Simmonds, P.G., Flory, D., Diaz, A.V., Rushneck, D.R., Biller, J.E., and Lafleur, A.L. (1977) The search for organic substances and inorganic volatile compounds in the surface of Mars. J. Geophys. Res. 82:4641-4658.

Botta, O. and Bada, J.L. (2002) Extraterrestrial organic compounds in meteorites. Surveys in Geophysics 23:411-467.

Brechtel, R., Hohmann, W., Rüdiger, H., and Wätzig, H. (1995) Control of the electroosmotic flow by metal-salt-containing buffers. I. Chromatogr. A 716:97-105.

Carlson, R.W., Johnson, R.E., and Anderson, M.S. (1999) Sulfuric acid on Europa and the radiolytic sulfur cycle. Science 286: 97-99.

Cavicchioli, R. (2002) Extremophiles and the search for extraterrestrial life. Astrobiology 2:281-292.

Chaban, B., Ng, S.Y.M., and Jarrel, K.F. (2006) Archaeal habitatsfrom the extreme to the ordinary. Can. J. Microbiol. 52:73-116.

Chiesl, T.N., Chu, W.K., Stockton, A.M., Amashukeli, X., Grunthaner, F., and Mathies, R.A. (2009) Enhanced amine and amino acid analysis using Pacific Blue and the Mars Organic Analyzer microchip capillary electrophoresis system. Anal. Chem. 81: 2537-2544.

De Bernardo, S., Weigele, M., Toome, V., Manhart, K., Leimgruber, W., Böhlen, P., Stein, S., and Udenfriend, S. (1974) Studies on the reaction of fluorescamine with primary amines. Arch. Biochem. Biophys. 163:390-399.

Fernández-Remolar, D.C., Morris, R.V., Gruener, J.E., Amils, R., and Knoll, A.H. (2005) The Río Tinto Basin, Spain: mineralogy, sedimentary geobiology, and implications for interpretation of outcrop rocks at Meridiani Planum, Mars. Earth Planet. Sci. Lett. 240:149-167.

Glavin, D.P., Schubert, M., Botta, O., Kminek, G., and Bada, J.L. (2001) Detecting pyrolysis products from bacteria on Mars. Earth Planet. Sci. Lett. 185:1-5.

Glavin, D., Brinkerhoff, W., Dworkin, J., Eigenbrode, J., Franz, H., Mahaffy, P., Stern, J., Allamandola, L., Blake, D., Sandford, S., Amashukeli, X., Fisher, A., Grunthaner, F., Fries, M., Steele, A., Aubrey, A., Bada, J., Chiesl, T., Mathies, R., Bish, D., Chipera, S., and Corrigan, C. (2008) Astrobiology Sample Analysis Program (ASAP) for advanced life detection instrumentation development and calibration [abstract 2-05-O]. Astrobiology 8:297.

Klingelhöfer, G., Morris, R.V., Bernhardt, B., Schröder, C., Rodionov, D.S., de Souza, P.A., Jr., Yen, A., Gellert, R., Evlanov, E.N., Zubkov, E.N., Foh, J., Bonnes, U., Kankeleit, E., Gütlich, P., Ming, D.W., Renz, F., Wdowiak, T., Squyres, S.W., and Arvidson, R.E. (2004) Jarosite and hematite at Meridiani Planum from Opporutnity's Mössbauer Spectrometer. Science 306:1740-1745.

Kminek, G., Bada, J.L., Botta, O., Glavin, D.P., and Grunthaner, F. (2000) MOD: an organic detector for the future robotic exploration of Mars. Planet. Space Sci. 48:1087-1091.

Landers, J.P. (1997) Handbook of Capillary Electrophoresis, $2^{\text {nd }}$ ed., CRC Press, Boca Raton, FL.

Levin, G.V. and Straat, P.A. (1977) Recent results from the Viking labeled release experiment on Mars. J. Geophys. Res. 82:4663-4668.

Lowenstein, T.K. (2007) Ancient microorganisms in salt. McGraw-Hill 2008 Yearbook of Science and Technology, McGrawHill Professional, New York, pp 13-15.

Lu, Y. and Freeland, S. (2006) On the evolution of the standard amino-acid alphabet. Genome Biol. 7:102.

McCord, T.B., Hansen, G.B., Fanale, F.P., Carlson, R.W., Matson, D.L., Johnson, T.V., Smythe, W.D., Crowley, J.K., Martin, P.D., 
Ocampo, A., Hibbits, C.A., Granahan, J.C., and the NIMS Team. (1998) Salts on Europa's surface detected by Galileo's Near Infrared Mapping Spectrometer. Science 280:1242-1245.

Oyama, B. and Berdahl, B. (1977) The Viking gas exchange experiment results from Chryse and Utopia surface samples. J. Geophys. Res. 82:4669-4676.

Rieder, R., Economou, T., Wänke, H., Turkevich, A., Crisp, J., Brückner, J., Dreibus, G., and McSween, H.Y., Jr. (1997) The chemical composition of martian soil and rocks returned by the mobile alpha proton X-ray spectrometer: preliminary results from the X-ray mode. Science 278:1771-1774.

Schubert, B.A., Lowenstein, T.K., and Timofeeff, M.N. (2009) Microscopic identification of prokaryotes in modern and ancient halite, Saline Valley and Death Valley. Astrobiology 9:467-482.

Skelley, A.M. and Mathies, R.A. (2003) Chiral separation of fluorescamine-labeled amino acids using microfabricated capillary electrophoresis devices for extraterrestrial exploration. J. Chromatogr. A 1021:191-199.

Skelley, A.M., Scherer, J.R., Aubrey, A.D., Grover, W.H., Ivester, R.H.C., Ehrenfreund, P., Grunthaner, F.J., Bada, J.L., and Mathies, R.A. (2005) Development and evaluation of a microdevice for amino acid biomarker detection and analysis on Mars. Proc. Natl. Acad. Sci. U.S.A. 102:1041-1046.

Skelley, A.M., Cleaves, H.J., Jayarajah, C.N., Bada, J.L., and Mathies, R.A. (2006) Application of the Mars Organic Analyzer to nucleobase and amine biomarker detection. Astrobiology 6:824-837.

Skelley, A.M., Aubrey, A.D., Willis, P.A., Amashukeli, X., Ehrenfreund, P., Bada, J.L., Grunthaner, F.J., and Mathies,
R.A. (2007) Organic amine biomarker detection in the Yungay region of the Atacama Desert with the Urey instrument. I. Geophys. Res. 112:1-10.

Squyres, S.W., Grotzinger, J.P., Arvidson, R.E., Bell, J.F., III, Calvin, W., Christensen, P.R., Clark, B.C., Crisp, J.A., Farrand, W.H., Herkenhoff, K.E., Johnson, J.R., Klingelhöfer, G, Knoll, A.H., McLennan, S.M., McSween, H.Y., Jr., Morris, R.V., Rice, J.W., Jr., Rieder, R., and Soderblom, L.A. (2004) In situ evidence for an ancient aqueous environment at Meridiani Planum, Mars. Science 306:1709-1714.

Stockton, A.M., Chiesl, T.N., Scherer, J.R., and Mathies, R.A. (2009) Polycyclic aromatic hydrocarbon (PAH) analysis with the Mars Organic Analyzer microchip capillary electrophoresis system. Anal. Chem. 81:790-796

Waite, J.H., Jr., Combi, M.R., Ip, W.-H., Cravens, T.E., McNutt, R.L., Jr., Kasprzak, W., Yelle, R., Luhmann, J., Niemann, J., Gell, D., Magee, B., Fletcher, G., Lunine, J., and Tseng, W.-L. (2006) Cassini Ion and Neutral Mass Spectrometer: Enceladus plume composition and structure. Science 311:1419-1422.

Zent, A.P. and McKay, C.P. (1994) The chemical reactivity of the martian soil and implications for future missions. Icarus 108:146-157.
Address correspondence to: Richard A. Mathies Department of Chemistry University of California Berkeley, CA 94720

E-mail: ramathies@berkeley.edu 
